\title{
Guido Strunk*
}

\section{Operationalizing Career Complexity}

There are a growing number of studies describing developments in the labour market, in employer-employee relationships, and in individual careers in a very similar way. The discussion about work force flexibility and the challenges for HRM to handle scattered arrangements is often justified by a growing complexity caused by the driving forces of globalization, virtualization, demographic developments or changes in values. However, so far there is no empirical evidence for that complexity hypothesis in individual careers. The primary aim of this article is to approach the complexity hypothesis of career research on the basis of a sound definition for complexity and to test the complexity hypothesis for data from the Vienna Career Panel Project.

Key words: complexity, career research, dynamic systems theories

Guido Strunk, Dipl.-Psych. Dr. Dr., Research Institute for Health Care Management and Health Care Economics, WU Vienna University of Economics and Business, Althanstr. 51, A - 1090 Vienna, Austria. E-mail: guido.strunk@wu.ac.at.

** Article received: August 26, 2008

Revised version accepted after double blind review: September 16, 2009. 


\section{Introduction}

Strategic management inevitably involves forethought and planning (Mintzberg 1994/2000), which is an easy task in an ordered and predictable environment, but becomes increasingly difficult in an unstable, turbulent and complex world. Since the early 1990s, this dilemma has been a controversial theme in strategic management (Mintzberg-Ansoff-controversy, e.g. Mintzberg 1990; Ansoff 1991). "Indeed sometimes organizations also need to function during periods of unpredictability, when they cannot possibly hope to articulate any viable strategy. The danger during such periods is not the lack of explicit strategy but exactly the opposite - "premature closure"' (Mintzberg 1990: 184).

There is a similar line of argumentation in the context of the so-called "make-orbuy" decision in human resource management (HRM). The "make-or-buy" decision is one of the core questions in human resource management (Miles/Snow 1984): Is it better to develop human capital internally or to purchase it on the external labour market? "Although the make-or-buy distinction is admittedly simplistic, the growing number of subtle variations on this theme makes the effective management of employment at once more complicated and more directly related to organizational effectiveness" (Lepak/Snell 1999: 31). It is therefore essential for strategic HRM to distinguish between different types of employees and to build an appropriate make-or-buy strategy for each of them. An influential model, developed by Lepak and Snell (1999), is based on transaction cost economics (Coase 1937; Williamson 1975), human capital theory (Becker 1964), and the resource-based view of the firm (Prahalad/Hamel 1990; Barney 1991). Key variables of their so-called "HR architecture" are the uniqueness of human capital and its value for the organization, which leads to the following assumption: unique human capital with a high value for the organization has to be developed internally, while human capital of low value and little uniqueness can be easily purchased from the external labour market. However, decisions have to be made on the value and uniqueness of the human capital in question. Moreover, a future development of these two variables and all other determinants possibly effecting them (e.g. future technological and market developments, trends in labour market and in educational systems) has to be taken into account. Although the strategic HRM architecture, as developed by Lepak and Snell (1999), is theoretically sound and of practical importance, it is unable to handle those uncertainties.

There is therefore a growing literature discussing the unpredictability of labour markets, working arrangements, and individual careers. Case studies (Koene/Van Riemsdijk 2005) and data from international surveys (Brewster et al. 2004) on flexible working arrangements are interpreted in the light of a growing "turbulence" (Polley 1997; Gooderham et al. 2004: 15), a rising “complexity" (Lissack 1999: 110; Bird et al. 2002), more "discontinuity" of developments (Weick/Berlinger 1989), organisational "instability" (Adamson et al. 1998: 255), and the increasing "unpredictability" of markets (Keen 1997: 172), technology (Technology Futures Analysis Methods Working Group 2004), society (Gergen 1993), and employment (Bird et al. 2002: 3; Lichtenstein et al. 2002: 32). With respect to Ofori-Dankwa and Julian (2001: 415; see also Rosser 1999) I will subsume these causes and criteria of "uncertainty", "turbu- 
lence" and so on under the term "complexity" (a more precise definition is given later on).

It is the basic idea of this article that the assumed growing complexity plays a key role for strategic HRM. First of all, the growing complexity is a central argument for more work force flexibility. Additionally, a more scattered and diverse work force is in turn a driving force for more complexity: it leads to an increasing unpredictability of individual careers and the irregular development of human capital, which is scattered by such chaotic career trajectories.

Since the late 1990s the discussion about work force flexibility has become one of the most central topics in HRM (Kalleberg 2001, 2003). Additionally, organizational research on flexibility (Volberda 1998) stresses the critical role of HRM in enabling organizations to react promptly to new developments (Kalleberg 2003). Also from an economic point of view flexible working practices are considered to be helpful in reducing unemployment rates and in enlarging the permeability of labour market segments (Brewster et al. 1997). Empirically numerous indicators are signalling an increased variety in employer-employee relationships (Eurostat 1998; OECD 2008). Classical fixed-term contracts are more and more complemented, if not replaced by flexible working arrangements like part-time, agency and on-call work, temporary and daily employment, telework, flexi-time, etc. (Ogura 2005, for a comparative view over Europe: Brewster et al. 2004).

These developments did not leave careers untouched. Several influential writers have proclaimed a transition leading to new and complex forms of careers (e.g. Arthur/Rousseau 1996; Hall 1996a; Peiperl/Baruch 1997; Mayrhofer et al. 2000). Although differing in a number of claims, analyses, and expectations, they have at least two things in common:

First, professional careers are interpreted as being more complex than ever and this development is expected to increase in the future. The "traditional" model of a single line career starting with training in one's early career stages leading to a quite stable career path in the same profession - sometimes even in the same organizations for the rest of one's working life - is discussed as currently being replaced (e.g. Reitman/Schneer 2003). Second, the significance of organizations as the central arena for professional careers is hypothesized to decrease (Strunk et al. 2002; Mayrhofer et al. 2005b).

To sum up, there seems to be a circular causality between HRM practices and individual careers. On the one hand, the call for flexibility is leading to a higher variety of working arrangements, which may amplify career complexity. On the other hand, the so-called "new careers" are increasingly located outside of organizations, and therefore are no longer directed by the strategic planning of a HRM department. Thus, irrespective of their own use of flexible working practices, HRM has to deal with individual careers which may be more complex than traditional careers.

However, most articles remain theoretical about the consequences of an increased turbulence in individual careers (e.g. Adamson et al. 1998) and only a few empirical studies exist (e.g. Reitman/Schneer 2003). In addition, most of these studies are based on single case studies and anecdotal narrations (e.g. Arthur/Rousseau 1996) 
rather than on quantitative data. Therefore, the hypothesis of an increasing career complexity is empirically still open, but of great importance for strategic HRM. Besides a sound and comprehensive definition for the term "complexity", which seems to be a key concept (not only in career research), is missing so far. Such a definition would be helpful in certain ways:

Complexity as a new research lens. Proportions of part-time or other working arrangements are widely used key figures at the meso-level of the organization (e.g. Brewster et al. 2004). On a macro-level they are used for labour force research (e.g. Eurostat 1998; OECD 2008). A complexity measure for the individual career trajectory would add quantitative data for the characterization of the micro-level of individual career paths. Therefore, a complexity measure is also a characterization of a dynamic process (Ancona et al. 2001) in contrast to a cross-sectional analysis.

Complexity as an interdisciplinary construct. According to Mintzberg (1994/2000: 17) strategic management inevitably involves some thinking and planning ahead of time. This is a special problem in strategic HRM, which is not only influenced by the business environment but also by human change processes of individual employees. "As the business environment becomes steadily more turbulent, it is increasingly problematic for firms to create clear, coherent strategic plans" (Gooderham et al. 2004: 15). Thus measurements of "turbulence" - which is a good example for complexity in physics (Ruelle/Takens 1971) - may be of some use for monitoring not only individual careers but also the business environment (e.g. on stock market complexity: Scheinkman/LeBaron 1989) and the organization itself (e.g. Thiétart/Forgues 1995; Polley 1997; Dooley/Van de Ven 1999).

This issue of defining complexity is addressed here from the viewpoint of dynamic systems theories (e.g. Haken/Schiepek 2006; Strunk/Schiepek 2006). Dynamic systems theories - commonly known also as chaos theory - contain a set of theories assessing the dynamic patterns generated by complex systems. Complexity, turbulence, and unpredictability are key concepts of dynamic systems theories, so it is hardly surprising that they provide theoretical concepts as well as empirical methods to investigate the complexity of dynamic processes (e.g. Tsonis 1992; Schreiber 1999). The aim of the present work is to assess the suitability of both, the theoretical conceptualizations of complexity as well as the corresponding empirical methods, for analysing changes and the changed situation in individual careers between 1970 and 1990.

The paper is structured as follows: In the first section I discuss three types of dynamic processes, resulting in a definition of complexity. Based on empirical data, the hypothesis of a growing career complexity is tested. Finally, the findings are discussed in the light of strategic HRM.

\section{What is complexity?}

Loosely speaking, complexity can be seen as a principal lack of information about future developments. If one is unable to predict the future trajectory of a system in principal, the system is called a complex system. However, if unpredictability is only based on a lack of information of the current state of the system or its history, predictability is only a question of knowledge. Therefore the term complexity does not 
seem to be appropriate in such a case. Theories on dynamical systems show that chaotic systems are not predictable in the long run, even if the knowledge of the current state of the system and its history is known with an arbitrary precision. It is sometimes said that such chaotic systems are mimicking randomness (e.g. Stewart 2002: 12). But, they are more ordered than a purely random process (e.g. an der Heiden 1996). In the following, I will elaborate this argument in more detail.

\subsection{Three Types of Dynamic Patterns}

The term "complexity" is very popular in literature; hence, it is not surprising that there is not a single applicable definition (Rosser 1999). Under the disillusioning title „From Complexity to Perplexity“, Horgan (1995) for instance cites the attempt of Seth Lloyd from the MIT to clearly define complexity: he ended up with a list of 45 different definitions. Most of the quoted definitions are based on physics, mathematics, and information theory (Shannon 1948) and assess whether a systems behaviour is calculable or not (Kolmogorov 1965; Zvonkin/Levin 1970; Chaitin 1974). In summary, complexity can be seen as a phenomenon in the tension field between simple order and blind randomness (Figure 1).

Figure 1: Complexity in the tension field between order and randomness Complexity

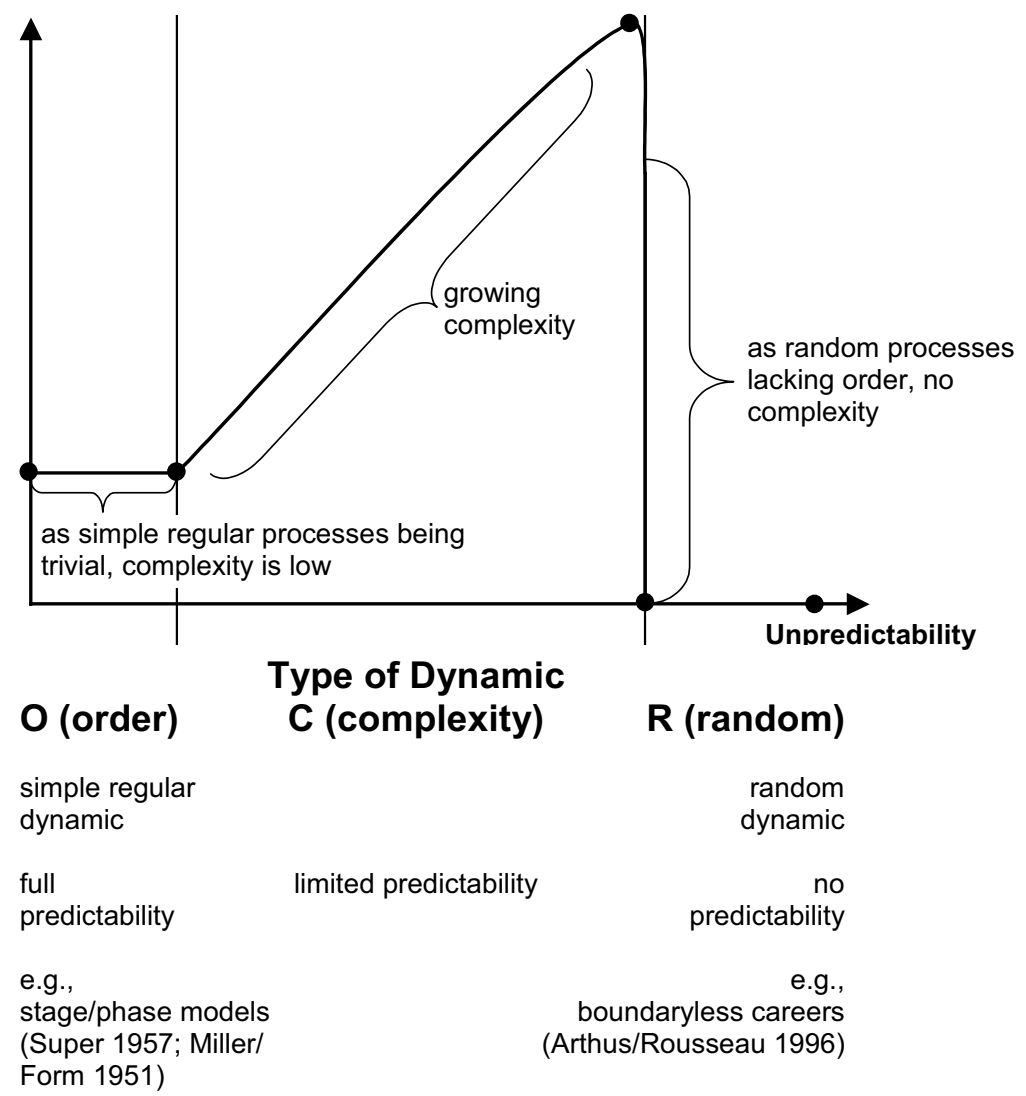


Traditionally, order and randomness are the only behavioural patterns known by classical physics and the sciences (e.g. classical Newtonian mechanics). A system is seen as strictly bound to the rules of causality and is thereby totally determined by its physical laws (Gunaratne 2004). By knowing the mechanisms, the behaviour of a system can be predicted with arbitrary precision (de Laplace 1996/1814). "Complicated systems" involving a larger number of laws are harder to analyse; yet, they are nevertheless assumed to be completely predictable, and consequently not complex. Below, I will call those principally-ordered processes "dynamics of type O" (O stands for order).

On the other hand, randomness is considered as the absence of laws. While on a theoretical level a complete absence of laws is unthinkable, in practice the throwing of dice is unpredictable from the knowledge of the previous outcome. Successive results from dice are uncorrelated; hence, there is no law to predict one from the other. In that sense, playing dice is a random process. In the following, I will call that randomness a "dynamic of type R" ( $R$ stands for randomness).

Complexity is therefore best seen as something in-between the two classical types of processes. It is located in the tension field between order and randomness, but is not identical with one or the other. Consequently, it is a quality of its own, showing both order and unpredictability simultaneously. Thus, complexity seems to be a paradox of contradicting principles. This can be considered as a major reason why it has taken considerable time to understand this phenomenon. No theory on complexity is much older than 50 years (e.g. Prigogine 1955; Lorenz 1963; Haken 1970), and most empirical methods are even younger (e.g. Grassberger/Procaccia 1983b, 1983a).

Common thinking is strongly influenced by classical Newtonian principals, and therefore it seems to be impossible to think of ordered but unpredictable systems. One of the most surprising findings of chaos theory (Poincaré 1908; Lorenz 1963) is the fact that a chaotic system can not be predicted in detail - even if the mathematical equation characterizing the system is known. But as mathematical equations are involved, there must also be some sort of order in that random-looking behaviour (c.f. e.g. Schuster 1989). Based on methods from chaos theory, this order can be identified and its complexity can be quantified (Grassberger/Procaccia 1983b, 1983a; Wolf et al. 1985; Schreiber 1999). Thus, chaos research shows that a chaotic system is a deterministic and ordered system which mimics randomness (Stewart 2002: 12). In the following I will call that complex behaviour a "dynamic of type C" (C stands for complexity).

\subsection{Dynamic concepts in career research}

Since chaos theory is not well known in HRM and career research, concepts to deal with the dynamics of careers are either based on models of type $\mathrm{O}$ (simple order) or more recently on type $\mathrm{R}$ processes (random). Most of the classical models of occupational developments merely discuss type O dynamics. Super's (1957) career stages, Miller and Form's (1951) phase model, as well as other works on career stages (e.g. Hall/Nougaim 1968; Veiga 1971, 1983; Cron 1984; Cron/Slocum 1986; Aryee et al. 1994) belong to type O dynamics. The same holds for most of Super's (1957) career pattern. However, he also mentions a so-called instable career, which is most likely based on a random type dynamics. Similarly, Driver (1982) has introduced two 
nonlinear career patterns. The so-called spiral career is defined by recurring cycles, in which someone follows a career for a limited time, makes an important change, and starts her or his career again in an other field, also for a limited time, before she or he begins somewhere else again (Brousseau et al. 1996). Although this career is not a linear one, the spiral pattern is ordered like a type $\mathrm{O}$ dynamic. The second nonlinear career pattern introduced by Driver (1982) is called a transitory career. It is defined by numerous career transitions without a logical connection to an overall career theme. This career can therefore be interpreted as a random type. Although Driver's ideas are interesting for the understanding of new careers, only few empirical studies are based on his concepts (Sullivan et al. 1998: 167, cf. Venne 2001).

Super (1990), influenced by the growing interest in nonlinear careers, revises his classical system of career stages. Much more than Driver (1982) he stresses the cyclic nature of new careers. The formerly close connection between career stage and age is eliminated; a frequent recycling through stages is seen as a normal pattern, and a regression to former stages while facing new challenges is no longer interpreted as a weakness but as a helpful way to deal with problems. Coming from another theoretical viewpoint, Mayrhofer et al. (2000: 20) also discuss new forms of career as a set of "many short learning cycles over the whole span of a person's life". Although both concepts accept external random shocks as triggers for the start of a new cycle, the basic model is still based on an ordered dynamic pattern of type $\mathrm{O}$.

There are also examples for career theories which seem to be of type R. According to the definition given above, a dynamic is called random if there is no mechanism which allows the prediction of a future change of the system on the basis of its previous trajectory. Most concepts about "new careers" are no longer interested in such mechanisms and patterns in career pathways. On the contrary, the lack of predefined career lines is interpreted as a chance for achieving more freedom. This does not deny the fact that in retrospect people are able to make sense also of a new career. Examples are the so-called "boundaryless" career (Arthur 1994), the protean career (Hall 1976; Hall 1996b; Hall 2003), and the chronic flexible career (Mayrhofer et al. 2000).

Concepts on new careers share a focus on the role of the individual, which is seen as active creator of his or her own career. In a world of boundaryless careers, the individual has to decide the path he or she wants to follow (Hall/Mirvis 1996). However, if human behaviour and decision-making is not random (and there is strong evidence that it cannot be considered as such), a personally-created career should be more complex than a career in one single organization, yet, it should not be random. So it seems that career patterns are also appealing issues for boundaryless, protean, or chronic flexible careers.

Interestingly, no theory has been developed for type $\mathrm{C}$ careers. This lack of concepts is surprising for three reasons: First, it seems to be clear that careers of type O are no longer the dominant career patterns in Western industrial nations (Drodge 2002: 51). Second, purely random processes are not plausible and not very likely, even if careers are boundaryless. Third, complexity can be understood as organized in an erratic and chaotic but nevertheless ordered way. Thus, a dynamic of type $\mathrm{C}$ is understandable as a consequence of a self-organizing process of a dynamic career system, which is also influenced by HRM practices and vice versa. 


\subsection{Measuring complexity}

As seen above, complexity is not easy to define and therefore not easy to measure. Most complexity measures are searching for patterns in time series data from a system. Loosely speaking, the algorithms follow the line of events in the time series and observe recurring sequences. Therefore, complexity measures are based on a dynamical viewpoint, taking into account time as a new research lens (Ancona et al. 2001).

It is helpful to discuss that aspect in more detail by using some examples. The numbers of part-time or temporary workers, for instance, are widely-used statistics that show an increasing number of such flexible working practices. This may be a sign of more complexity. But, according to the given definition this would only be the case if there were a lack of predictability in it. But that cannot be seen from the statistics alone. On the contrary, one may think of work force flexibility as a strategic tool, which is used to reduce uncertainty (e.g. Lepak/Snell 1999). From the perspective of each individual career, a growing number of job-transitions (DeFillippi/Arthur 1994) is not necessarily an indicator for complexity. There are several professions in which a comparatively high number of job transitions are the norm, and are therefore a predictable part of the career. It is, however, possible to investigate the unpredictability of a career transition by using additional subjective data about the desirability of such a transition (Higgins 2001).

Complexity measures from dynamic systems theories are able to quantify the unpredictability of a career trajectory without referring to additional subjective data. Such methods have existed since the early 1980s. The most important measure is the correlation dimension (Grassberger/Procaccia 1983b, 1983a). It is based on Mandelbrot's (e.g. 1987) work on fractals and on Ruelle and Takens' (1971) hypothesis that chaos can be identified by its fractal structure. The main idea of the fractal dimension is comparable to the outcome of the well-known factor analysis. A factor analysis tries to identify how many dimensions are sufficient in order to describe the structure of a data set. If the dimensional structure of a huge data set is limited to a handful of factors, this data set can be interpreted as being less complicated than a data set having a solution with more dimensions. Additional information is given by the explanation of variance, which can be interpreted as the amount of randomness present in the data. The results from the correlation dimension are very similar to those of factor analysis. However, the correlation dimension is able to characterize not only a complicated data set but also complex dynamics. A surprising result from fractal geometrics shows that for a complex dynamic system exhibiting chaos, the number of dimensions is not a natural but a floating-point number (Ruelle/Takens 1971). Additionally, a non-natural number of dimensions indicates (in most cases) chaos, whereas a natural number indicates a simple type $\mathrm{O}$ process. Thus, the number of dimensions is a quantification of the complexity of a dynamic system (Fell et al. 2000: 486).

Despite its great popularity, the correlation dimension has some limitations. One problem is the lack of a test statistic for the accuracy of the dimensional solution. Thus, the correlation dimension is not a test for complexity in a statistical sense. A sound statistical test is normally based on the rejection of a plausible null-hypothesis. Such a null-hypothesis is, in the case of complexity, given either by a test for a type $\mathrm{O}$ 
dynamics or by a test for randomness (type $\mathrm{R}$ dynamics). The rejection of a type $\mathrm{O}$ dynamics is often based on the inspection of the data plot with naked eye. A test for randomness requires more effort. For this reasons the correlation dimension, in economic research (e.g. Scheinkman/LeBaron 1989), is often combined with the BDS test (Brock et al. 1987; Brock et al. 1996) in order to test for randomness as a nullhypothesis.

The BDS test is not limited to identify a certain type of correlation in a given data set (e.g. a linear correlation) but searches for recurring patterns within the data. Although recurring patterns are normally an indication for non-random processes, they can also occur at random with a certain probability. As the probability for randomly recurring sequences is mathematically known, it can be tested against the given data set. In order to identify a dynamic of type $\mathrm{C}$, the null hypothesis of randomness has to be rejected by the BDS test.

\section{Testing the complexity hypothesis}

The discussion so far can be summed up as follows: there are a growing number of studies describing developments in the labour market, in employer-employee relationships, and in individual careers in a very similar way. The discussion about work force flexibility and the challenges for HRM to handle such scattered arrangements is often justified by a growing complexity caused by driving forces like globalization, virtualization, demographic developments, or changes in values. However, until now there has been no empirical evidence for this complexity hypothesis in career research that is based on a sound definition of complexity. This argumentation can be summed up in a first hypothesis:

Hypothesis 1: Comparing careers that started in the 1970s with careers that have started in the 1990s, the later careers are more complex than the earlier careers.

In addition, as stated above, many scholars argue that for a number of decades, simple type $\mathrm{O}$ careers are no longer the dominant pattern in Western industrial nations. This leads to the following hypothesis:

Hypothesis 2: For both the 1970s and the 1990s cohorts, the observed career patterns mirror a complex process more so than an ordered or a random process.

As stated in the Hypothesis 2, a complex career is not a random process. With regard to the BDS test, this can be formulated more precisely:

Hypothesis 3: Careers from neither the earlier nor the later cohort are random processes.

In order to test the first two hypotheses, I employ the correlation dimension to quantify complexity and the BDS test to test against randomness.

\subsection{Methods}

Started in 2000 and supported by the Austrian Science Fund (FWF), the Vienna Career Panel Project (ViCaPP) attempts to explore the professional careers of business graduates in Austria (e.g. Mayrhofer et al. 2002; Mayrhofer et al. 2005a). In addition to 
a sample of 650 graduates who successfully completed their studies at the Vienna University of Economics and Business Administration (WU Wien) between 2000 and 2002, data were also collected from persons having graduated several years prior.

In summer 2002, two cohorts of former graduates of the WU Wien were asked to participate in a survey that consisted of a mail questionnaire as well as a highly standardized professional development questionnaire that was filled out during a face-toface interview. The two cohorts consisted of graduates that finished their studies around 1970 and around 1990, respectively. Up until now, 361 former WU graduates have participated in this study, of which 111 belong to the 1970s cohort and 250 to the 1990s cohort.

Based on a curriculum-vitae-like list of professional activities for each person, their professional development was charted for each year since their graduation along several variables, such as income, career satisfaction, attributed career success. Among many other variables that were collected, the survey resulted in a total of twelve time series per person, with a sampling frequency of one year (table 1).

Table 1: Measurements

\begin{tabular}{|c|c|c|c|c|c|c|c|c|c|c|}
\hline & & & $\begin{array}{l}970 \\
2 \text { years }\end{array}$ & & & & & & $\begin{array}{l}970 \\
\text { careera }\end{array}$ & \\
\hline & & Mean & SD & $\mathrm{N}^{\mathrm{b}}$ & Mean & SD & $\mathrm{N}$ & Mean & SD & $\mathrm{N}$ \\
\hline I. & Objective Career & 5.89 & 1.79 & 103 & 6.15 & 1.72 & 192 & 7.66 & 1.88 & 101 \\
\hline & Items: & & & & & & & & & \\
\hline & Number of $s$ & & & & & & & & & \\
\hline & Proportion 0 & ial/leade & p tasks & oppc & to "har & on" tas & & & & \\
\hline & Total annua & & & & & & & & & \\
\hline & Proportion o & gy" inves & nto jo & & & & & & & \\
\hline
\end{tabular}

II. Subjective Career

\begin{tabular}{rrrrrrrrr}
\hline Mean & SD & N & Mean & SD & N & Mean & SD & N \\
\hline 8.29 & 1.63 & 103 & 8.29 & 1.51 & 192 & 8.14 & 1.69 & 101 \\
\hline
\end{tabular}

Items:

5. Career satisfaction.

6. Attributed career success.

7. Security and calculability of career-related prospects.

8. Closeness and intensity of professional relations.

9. How easily another adequate job could be found should the need arise.

\begin{tabular}{llrrrrrrrr}
\cline { 2 - 9 } III. & Mean & SD & N & Mean & SD & N & Mean & SD & N \\
\cline { 2 - 10 } & 7.31 & 1.83 & 103 & 6.99 & 1.94 & 192 & 6.62 & 2.09 & 101 \\
\hline Items: Stability & & & & & & & \\
10. Stability of professional relations. & & & & & & & \\
11. Stability of work content. \\
12. Subjection of career-related prospects to specific external actors and/or constraints.
\end{tabular}

a Data for "late career" was collected for the same 12 calendar years as for the 1990 s cohort.

b N is the number of subjects with complete datasets in the 12 year time span.

SD: Standard deviation; N: Number of subjects. 
All measurements except income and number of subordinates were collected via 11point rating scales. In order to adjust all items on a similar scale, values for income and number of subordinates were recoded into 11 distinct categories by using percentile rank scales. Based on a factor analysis, the 12 measurements were arranged into three factors, which can be interpreted as subjective and objective career and as career stability. The analysis is based on these three factors (mean sum scores) and on the first 12 years of professional career after graduation. The data used here were collected retrospectively. It seems plausible that this task was more difficult for a person with more than 30 years of professional experience than for someone who started his or her professional career around 12 years ago. Therefore, differences in complexity may partly be a consequence of the "mellowing" effect of time on career recollections. To control this memory effect, additional data from the 1970s cohort, which was collected for the same calendar years as for the 1990s cohort, was also analyzed. Those data sets from the same calendar years may be influenced by the same memory effects.

All methods from chaos research theoretically require an infinitely long time series to reliably determine the complexity of a given process. A set of 1,000 sampling points is generally regarded as a small data set, but is sufficient for the calculation of the correlation dimension (Strunk/Schiepek 2006: 211). But, this is still far beyond the 12 sampling points provided by the 12 career years of the 1990 s cohort. Therefore, the time series of all persons in each cohort are aggregated to a single quasi time series. Such a procedure requires that the complexity of career paths do not differ significantly between the individual cases. As this cannot be examined at the outset, 100 different variants of the time series for each of the two cohorts were generated and calculated separately. Additionally, lacking homogeneity should also result in a random "overall" time series.

\subsection{Sample description}

The structural differences between the two cohorts are not very pronounced. If one examines the first 12 years of career, the proportions of self-employed persons vs. salaried employees resemble each other in both cohorts. About $68 \%$ of the 1990 s cohort have never been self-employed during their first 12 years of professional experience, while the respective proportion for the 1970 s cohort is about $76 \%$. Although the difference seems considerable at first sight, it is not statistically significant (Fisher test: $\mathrm{p}($ two-tailed $)=0.175)$. Those persons that claimed to have been self-employed during the first 12 years of their career have mostly done so only for a limited time.

The differences regarding gender were more conspicuous. Women are quite underrepresented in the 1970 s cohort compared to the 1990 s cohort, with $13 \%$ and $38 \%$ respectively. This is due to the fact that there were fewer women who began and finished their studies in the 1970s. In the years 1972/73, the proportion of female graduates was $16 \%$, compared to $39 \%$ in $1989 / 90$. For the dataset of the 1990 s cohort income differences between men and women are analysed and discussed in Strunk and Hermann (2009).

Mean age was 37.1 years ( \pm 2.0 years) for the women and 37.9 years $( \pm 3.8$ years) for the men in the 1990s cohort, and 55.6 years ( \pm 2.1 years) for the women and 57.4 years $( \pm 3.2$ years) for the men in the 1970 s cohort. 


\subsection{Results}

First results can be found by just looking at the 3-dimensional plot of the quasi-time series. The three dimensions are identical with the three factors from factor analysis (see table 1). If careers are organized as simple processes of type $\mathrm{O}$, the 3-dimensional plot may result in a bundle of straight lines or may be ordered in any other simple way. It can be seen from figure 2 that both plots are not that simple. Therefore, not even careers from the 1970s are of type O.

Figure 2: 3-dimensional plot of career trajectories from quasi-time series
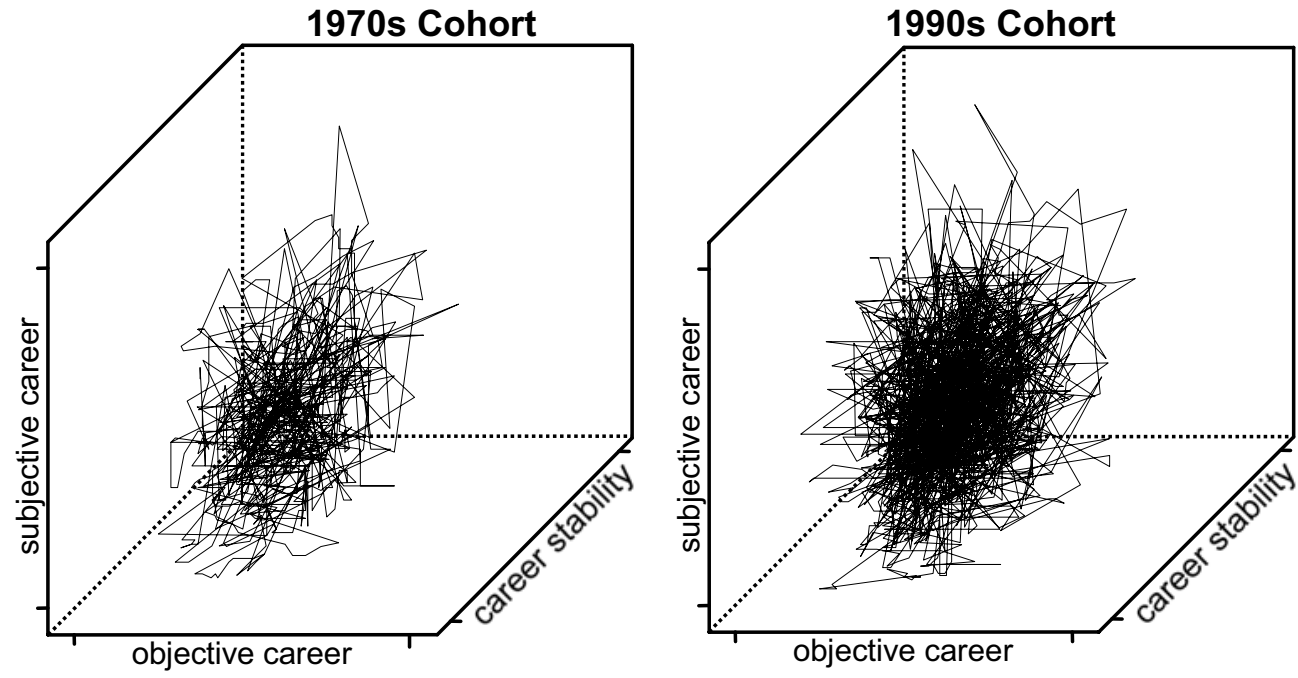

The complexity hypothesis is fully supported by the results from the correlation dimension (table 2). The correlation dimension for the 1990s cohort is approximately one dimension higher than in the 1970s cohort. The differences in complexity are not only significant, but also cohort effects can explain $97 \%$ of variance. Additionally, there are only marginal differences between the results of the calculations for the 100 time-series variants. This indicates that the procedure of aggregating the individual time series in a single quasi time series is valid.

Table 2: Results from correlation dimension

\begin{tabular}{|c|c|c|c|c|c|}
\hline & Mean & SD & Min & $\operatorname{Max}$ & $\mathrm{Na}^{\mathrm{a}}$ \\
\hline 1970s cohort (first 12 years of career) ${ }^{* *}$ & 3.424 & 0.179 & 3.026 & 3.707 & 103 \\
\hline 1990s cohort (first 12 years of career) ${ }^{* *}$ & 4.704 & 0.063 & 4.475 & 4.817 & 192 \\
\hline $\begin{array}{l}\text { 1970s cohort } \\
\text { (same calendar years as for the first } 12 \text { years of the } 1990 \text { s cohort) }\end{array}$ & 2.802 & 0.149 & 2.410 & 3.073 & \\
\hline
\end{tabular}

a $\mathrm{N}$ is the number of subjects with complete datasets. Calculation of mean is however based on 100 quasi-time series.

** Significant differences with $p(1$-tailed) $<=0.01$. Effect-size is $97 \%$ explanation of variance.

SD: Standard deviation; Min: Minimum; Max: Maximum; N: Number of subjects.

The geometrical structures of the quasi-time series for both cohorts are identified as fractals and therefore representations of dynamical structures of type C. Additionally, 
the complexity of the data set from the 1970s cohort that was collected for the same calendar years as the data from the 1990s cohort is much less complex, showing that the observed differences are not based only on memory effects.

Additional evidence comes from the BDS test. For both cohorts, the null hypothesis of white noise is rejected significantly. Thus, none of the quasi-time series are random processes. In order to assess these results in more detail, each quasi-time series was randomized prior to the calculation of the BDS test. This procedure destroys any order contained in the complex data sets generating white noise. This randomization test is also in favour of a complex - but not a random - process.

\section{Discussion and outlook}

The starting point of this article was the discussion about the possibility of a rational basis for the make-or-buy decision in strategic HRM. There is a controversial discussion about the limits of prediction and therefore the limits of strategic planning in the light of a growing "turbulence", "complexity", and "discontinuity".

The so-called "complexity hypothesis", which is based on supposing a growing career complexity, is one of the most substantial leitmotivs of career research since the 1990s. Related themes investigate the consequences of highly complex careers for the individual. The presumed consequences range from psychological well-being negatively influenced by a loss of security and stability (Gerdtham/Johannesson 2003, Strunk/Schiepek 2006: 156) to strengthening the individual by allowing more freedom in the choice of his or her path within the boundaryless career (Hall/Mirvis 1996). Although the list of hypothetical consequences is long (see, e.g. Sullivan et al. 1998), empirical evidence is rare due to missing or equivocal definitions of complexity.

The present work shows that the use of concepts from dynamical systems theories can be employed to better understand new developments in careers. The presented theories and methods not only offer a precise definition of complexity but can also be directly implemented using algorithms from chaos theory. As has been shown, these algorithms can be applied to career research data sets. Therefore, the definition of complexity is not only theoretically sound but also a first step for building a better empirical basis of the complexity hypothesis.

Limitations of the present study are based on the problem that the correlation dimension is an aggregate measure and cannot be employed at the individual level. This is a general problem of complexity measures, because their calculations are valid only for large data sets. However, there are some newly developed methods based on algorithmic information theory (Kolmogorov 1965) and on permutation entropy (Bandt/Pompe 2002) which may also be useful for the individual level of career research. In contrast to the methods used in the present paper, those measurements are not able to differentiate between complexity and randomness.

The presented empirical evidence clearly supports the complexity hypothesis. Neither models of type $\mathrm{O}$ nor of type $\mathrm{R}$ are appropriate concepts to explain the identified structures in the analysed datasets. The increase in career complexity between the older and the younger cohort provide further support for the complexity hypothesis. The findings are of some importance for the make-or-buy decision in strategic HRM: 
Appropriate handling of complexity: The analyses for the two cohorts show strong evidence for complex career processes, not only in the younger but also in the 1970s cohort. So the promised path of a linear career, as Reitman and Schneer (2003) put it, was not true even forty years ago. The findings are also, however, in favour of a dramatically increasing complexity. That means that the prediction of career lines is more difficult for the younger cohort. The complexity measures used are able to quantify these developments in a sound mathematical manner. Therefore, "complexity" is no longer a word without a concrete meaning. Furthermore, it was shown that models from dynamic systems theories "can handle the complexity of behaviour exhibited by the various systems within the purview of management research" (Kauffman 1994: 209). If one is able to measure the complexity of different groups of employees, or age cohorts, one may be able to handle it in future.

Complexity is leading to a looser coupling: Complexity, which generally means uncertainty and unpredictability, is increasingly turning into a self-fulfilling prophecy. A classical sociological interpretation of professional careers stresses the function of the social orientation that can be drawn from beliefs about what a "normal" career is (Adamson et al. 1998: 253). Normality today is seen more and more in a highly complex career in which nothing is really known for certain. Currently, there is a broad discussion in the media about labour market insecurity in connection with the financial crisis and the impossibility of predicting future developments (e.g. Heuser 2008). The findings presented here are based on objective and reliable measurements about a growing uncertainty in individual career lines. As argued above, this uncertainty measurement is based not on the beliefs of the actors but on an objective quantity for the disappearing of patterns in individual careers. However, if individuals do not believe any longer in the classical and linear organizational career, this will affect his or her willingness to commit themselves to employers. "In the context of graduate careers, it seems that organizations are faced with something of a paradox. On the one hand, it is in the organizations' interests to perpetuate the illusion of predictability and stability in managerial career systems (in order, for example, to retain high-potential employees). However, if, in practice, organizations are no longer able to offer privileged routes to the top for the favoured few, how will they retain the cadre of high-potential staff they need to fill senior management positions in the future?" (Adamson et al. 1998: 256). Based on the Orton's and Weick's (1990) concept of loose coupling, Mayerhofer et al. (2000) are arguing for a less stable and looser coupling between actors on the labour market (so-called "chronic flexibility"). Those developments may be of some danger for the internal development of high value and unique human capital, because such internal routes are bound to a high commitment on both sides.

However, these conclusions are meant as hypotheses for future research. Since it was the main goal of this article to clarify the term "complexity", further research is necessary to test the complexity hypothesis for different cohorts and samples.

\section{References}

Adamson S.J./Doherty N./Viney C. (1998): The Meanings of Career Revisited: Implications for Theory and Practice. In: British Journal of Management, 9: 251-259. 
an der Heiden U. (1996): Chaos und Ordnung, Zufall und Notwendigkeit. In: G. Küppers (Eds.), Chaos und Ordnung. Formen der Selbstorganisation in Natur und Gesellschaft. Stuttgart: Philipp Reclam jun.: 97-121.

Ancona D.G./Goodman P.S./Lawrence B.S./Tushman M.L. (2001): Time: A New Research Lens. In: Academy of Management Review, 26 (4): 645-663.

Ansoff H.I. (1991): Critique of Henry Mintzberg's "The Design School: Reconsidering the Basic Premises of Strategic Management". In: Strategic Management Journal, 12 (6): 449-461.

Arthur M.B. (1994): The Boundaryless Career: A New Perspective for Organizational Inquiry. In: Journal of Organizational Behavior, 15 (4): 295-306.

Arthur M.B./Rousseau D.M. (Eds.) (1996): The Boundaryless Career. A New Employment Principle for a New Organizational Era. New York: Oxford University Press.

Aryee S./Cha Y.W./Chew J. (1994): An Investigation of the Predictors and Outcomes of Career Commitment in Three Career Stages. In: Journal of Vocational Behavior, 44: 1-16.

Bandt C./Pompe B. (2002): Permutation Entropy: A Natural Complexity Measure for Time Series. In: Physical Review Letters, 88 (17): 174102-1 - 174102-4.

Barney J. (1991): Firm resources and sustained competitive advantage. In: Journal of Management, 17: 99129.

Becker G.S. (1964): Human capital. New York: Columbia University Press.

Bird A./Gunz H./Arthur M.B. (2002): Careers in a Complex World: The Search for New Perspectives from "New Science". In: M@n@gement, 5 (1): 1-14.

Brewster C./Mayrhofer W./Morley M. (Eds.) (2004): Human Resource Management in Europe. Evidence for Convergence? London: Elsevier Butterworth-Heinemann.

Brewster C./Mayne L./Valverde M.A./Kabst R. (1997): Flexibility in European Labour Markets? The Evidence Renewed. In: Employee Relations, 19 (6): 509-518.

Brock W.A./Dechert W.D./Scheinkman J. (1987): A Test for Independence Based on the Correlation Dimension, Working Paper No. 8702 (Revised Version, 1996: Brock, W.A., W.D. Dechert, J. Scheinkman \& B. LeBaron). Wisconsin, Houston, Chicago: University of Wisconsin, University of Houston and University of Chicago.

Brock W.A./Dechert D./Scheinkman J./LeBaron B. (1996): A test for independence based on the correlation dimension. In: Econometric Reviews, 15: 197-235.

Brousseau K.R./Driver M.J./Eneroth K./Larsson R. (1996): Career Pandemoniums: Realigning Organizations and Individuals. In: Academy of Management Executive, 10 (4): 52-66.

Chaitin G.J. (1974): Information Theoretic Computational Complexity. In: IEEE Transactions on Information Theory, IT20: 10-15.

Coase R.H. (1937): The nature of the firm. In: Economica, 4: 386-405.

Cron W.L. (1984): Industrial Salesperson Development: A Career Stages Perspective. In: Journal of Marketing, 48: 41-52.

Cron W.L./Slocum J.W. (1986): The Influence of Career Stages on Salespeople's Job Attitudes, Work Perception and Performance. In: Journal of Marketing Research, 23 (5): 119-129.

de Laplace P.S. (1996/1814): Philosophischer Versuch über die Wahrscheinlichkeit. Frankfurt am Main: Verlag Harri Deutsch.

DeFillippi R.J./Arthur M.B. (1994): The Boundaryless Career: A Competency-Based Perspective. In: Journal of Organizational Behavior, 15 (4): 307-324.

Dooley K.J./Van de Ven A.H. (1999): Explaining Complex Organizational Dynamics. In: Organization Science, 10 (3): 358-372.

Driver M.J. (1982): Career Concepts - A New Approach to Career Research. In: Human Resource Management: 23-32.

Drodge E.N. (2002): Career Counseling at the Confluence of Complexity Science and New Career. In: M@n@gement, 5 (1): 49-62.

Eurostat (Eds.) (1998): Labour Force Survey. Results 1997. Luxembourg: Office for Official Publications of the European Communities.

Fell J./Mann K./Röschke J./Gopinathan M.S. (2000): Nonlinear Analysis of Continuous ECG During Sleep II. Dynamical Measures. In: Biological Cybernetics, 82: 485-491. 
Gerdtham U.-G./Johannesson M. (2003): A Note on the Effect of Unemployment on Mortality. In: Journal of Health Economics, 22: 505-518.

Gergen K.J. (1993): Psychologie in der Postmoderne. In: systeme, 7 (1): 4-15.

Gooderham P./Morley M./Brewster C./Mayrhofer W. (2004): Human Resource Management: A Universal Concept? In: C. Brewster/Mayrhofer W./Morley M. (Eds.), Human Resource Management in Europe. Evidence for Convergence? 3-26.

Grassberger P./Procaccia I. (1983a): Measuring the Strangeness of strange Attractors. In: Physica D, 9: 189-208.

Grassberger P./Procaccia I. (1983b): On the Characterization of strange Attractors. In: Physical Review Letters, 50: 346-356.

Gunaratne S.A. (2004): Thank you Newton, Welcome Progogine: 'Unthinking' Old Paradigms and Empracing New Directions. Part 2: The Pragmatics. In: Communications, 29: 113-132.

Haken H. (Eds.) (1970): Laser Theory. Berlin: Springer.

Haken H./Schiepek G. (2006): Synergetik in der Psychologie. Selbstorganisation verstehen und gestalten. Göttingen: Hogrefe.

Hall D.T. (1976): Careers in Organizations. Santa Monica: Addison-Wesley.

Hall D.T. (Eds.) (1996a): The Career is Dead - Long Live the Career. A Relational Approach to Careers. San Francisco: Jossey-Bass Publishers.

Hall D.T. (1996b): Protean Careers of the 21st Century. In: Academy of Management Executive, 10 (4): 8-16.

Hall D.T. (2003): The Protean Career: A Quarter-Century Journey. In: Journal of Vocational Behavior, 65: $1-13$.

Hall D.T./Mirvis P.H. (1996): The New Protean Career. Psychological Success and the Path with a Heart. In: D.T. Hall (Eds.), The Career is Dead. Long Live the Career. A Relational Approach to Careers. San Francisco: Jossey-Bass Publishers: 15-45.

Hall D.T./Nougaim K. (1968): An Examination of Maslow's Need Hierarchy in an Organizational Setting. In: Organizational Behavior and Human Performance, 3: 12-35.

Heuser U.J. (2008): Kassandras Albtraum. In: Die Zeit, 23. Dezember (1): 31.

Higgins M.C. (2001): Changing Careers: The Effects of Social Context. In: Journal of Organizational Behavior, 22: 595-618.

Horgan J. (1995): From Complexity to Perplexity. In: Scientific American, 272 (6): 104-109.

Kalleberg A.L. (2001): Organizing Flexibility: The Flexible Firm in a New Century. In: British Journal of Industrial Relations, 39 (4): 479-504.

Kalleberg A.L. (2003): Flexible Firms and Labor Market Segmentation. In: Work and Occupation, 30 (2): 154-175.

Kauffman R.G. (1994): Multivariate Catastrophe Model Estimation: Method and Application. In: Academy of Management Journal, 37 (1): 206-221.

Keen S. (1997): From Stochastics to Complexity in Models of Economic Instability. In: Nonlinear Dynamics, Psychology, and Life Sciences, 1 (2): 151-172.

Koene B./Van Riemsdijk M. (2005): Managing Temporary Workers: Work Identity, Diversity, and Operational HR Choices. In: Human Resource Management Journal, 15 (1): 76-92.

Kolmogorov A.M. (1965): Three Approaches to the Definition of the Concept Quantity of Information. In: IEEE Transactions on Information Theory, IT14: 662-669.

Lepak D.P./Snell S.A. (1999): The Human Resource Architecture: Towards a Theory of Human Capital Allocation and Development. In: Academy of Management Review, 24 (1): 31-48.

Lichtenstein B.M.B./Ogilvie J.R./Mendenhall M. (2002): Non-Linear Dynamics in Entrepreneurial and Management Careers. In: M@n@gement, 5 (1):31-47.

Lissack M.R. (1999): Complexity: the Science, its Vocabulary, and its Relation to Organizations. In: Emergence, 1 (1): 110-126.

Lorenz E.N. (1963): Deterministic Non-Periodic Flow. In: Journal of Atmosphere Science, 20: 130-141.

Mandelbrot B.B. (1987): Die fraktale Geometrie der Natur. Basel: Birkhäuser.

Mayrhofer W./Meyer M./Steyrer J. (Eds.) (2005a): Macht? Erfolg? Reich? Glücklich? Einflussfaktoren auf Karrieren. Wien: Linde. 
Mayrhofer W./Steyrer J./Meyer M./Strunk G./Schiffinger M./Iellatchitch A. (2005b): Graduates' Career Aspirations and Individual Characteristics. In: Human Resource Management Journal, 15 (1): 38-56.

Mayrhofer W./Steyrer J./Meyer M./Erten C./Hermann A./Iellatchitch A./Mattl C./Strunk G. (2000): Towards a Habitus Based Concept of Managerial Careers. Paper presented at the Academy of Management, Toronto, Canada.

Mayrhofer W./Meyer M./Steyrer J./Iellatchitch A./Schiffinger M./Strunk G./Erten-Buch C./Hermann A./Mattl C. (2002): Einmal gut, immer gut? Einflussfaktoren auf Karrieren in "neuen" Karrierefeldern. In: Zeitschrift für Personalforschung, 16 (3): 392-414.

Miles R.E./Snow C.C. (1984): Designing Strategic Human Resource Systems. In: Organizational Dynamics, 13: 36-52.

Miller D./Form W. (1951): Industrial Sociology. New York: Harper.

Mintzberg H. (1990): The Design School: Reconsidering the Basic Promises of Strategic Management. In: Strategic Management Journal, 11 (3): 171-195.

Mintzberg H. (1994/2000): The Rise and Fall of Strategic Planning. London: Financial Times, Prentice Hall International.

OECD (2008): Labour Force Statistics 2008. OECD Publishing.

Ofori-Dankwa J./Julian S.D. (2001): Complexifying Organizational Theory: Illustrations Using Time Research. In: Academy of Management Review, 25 (3): 415-430.

Ogura K. (2005): International Comparison of Atypical Employment: Differing Concepts and Realities in Industrialized Countries. In: Japan Labor Review, 2 (2): 5-29.

Orton J.D./Weick K.E. (1990): Loosely Coupled Systems: A Reconceptualization. In: Academy of Management Review, 15 (2): 203-223.

Peiperl M./Baruch Y. (1997): Back to Square Zero: The Post-Corporate Career. In: Organizational Dynamics, 25 (4): 7-22.

Poincaré H. (1908): Science et méthode. Paris: Flammarion.

Polley D. (1997): Turbulence in Organizations: New Metaphors for Organizational Research. In: Organization Science, 8 (5): 445-457.

Prahalad C.K./Hamel G. (1990): The core competence of the corporation. In: Harvard Business Review, 68 (3): 79-91.

Prigogine I. (1955): Thermodynamics of Irreversible Processes. New York: Wiley.

Reitman F./Schneer J.A. (2003): The Promised Path: a Longitudinal Study of Managerial Careers Commitment. In: Journal of Managerial Psychology, 18 (1): 60-75.

Rosser J.B. (1999): On the Complexities of Complex Economic Dynamics. In: The Journal of Economic Perspectives, 14 (4): 169-192.

Ruelle D./Takens F. (1971): On the Nature of Turbulence. In: Communications in Mathematical Physics, 20: 167-192.

Scheinkman J.A./LeBaron B. (1989): Nonlinear Dynamics and Stock Returns. In: The Journal of Business, 62 (3): 311-337.

Schreiber T. (1999): Interdisciplinary Application of Nonlinear Time Series Methods. In: Physics Report, 308: 1-64.

Schuster H.G. (1989): Deterministic Chaos. Weinheim: VCH.

Shannon C.E. (1948): A Mathematical Theory of Communication. In: Bell System Technical Journal, 27: 379-423 and 623-656.

Stewart I. (2002): Does God Play Dice? The New Mathematics of Chaos (Second Edition). Malden: Blackwell Publishing.

Strunk G./Hermann A. (2009): Berufliche Chancengleichheit von Frauen und Männern. Eine empirische Untersuchung zum Gender Pay Gap. In: Zeitschrift für Personalforschung, 23(3): 237-257.

Strunk G./Schiepek G. (2006): Systemische Psychologie. Eine Einführung in die komplexen Grundlagen menschlichen Verhaltens. München: Spektrum Akademischer Verlag.

Strunk G./Steyrer J./Mattl C./Mayrhofer W. (2002): How Career Tactics and Personality Influence PostOrganizational Career Aspirations. Paper presented at the 25th International Congress of Applied Psychology, Singapore. 
Sullivan S.E./Carden W.A./Martin D.F. (1998): Careers in the Next Millennium: Directions for Future Research. In: Human Resource Management Review, 6 (2): 165-185.

Super D.E. (1957): The Psychology of Careers. New York: Harper \& Row.

Super D.E. (1990): A Life-Span, Life-Space Approach to Career Development. In: D. Brown/Brooks L. (Eds.), Career Choice and Development. San Francisco: Jossey-Bass: 197-261.

Technology Futures Analysis Methods Working Group (2004): Technology Futures Analysis: Toward Integration of the Field and New Methods. In: Technological Forecasting \& Social Change, 71: 287303.

Thiétart R.A./Forgues B. (1995): Chaos Theory and Organization. In: Organization Science, 6 (1): 19-31. Tsonis A.A. (1992): Chaos: From Theory to Applications. New York: Plenum Press.

Veiga J.F. (1971): A Behavioral Model of Middle-Manager Career Mobility: An Empirical Analysis. Kent: Kent State University.

Veiga J.F. (1983): Mobility Influences During Managerial Career Stages. In: Academy of Management Journal, 26 (1): 64-85.

Venne R.A. (2001): Population Aging in Canada and Japan: Implications for Labor Force and Career Patterns. In: Canadian Journal of Administrative Sciences, 18 (1): 40-49.

Volberda H.W. (1998): Building the Flexible Firm. Oxford: Oxford University Press.

Weick K.E./Berlinger L.R. (1989): Career Improvisation in Self-Designing Organizations. In: M.B. Arthur/Hall D.T./Lawrence B.S. (Eds.), Handbook of Career Theory. Cambridge: Cambridge University Press: 313-328.

Williamson O.E. (1975): Markets and hierarchies: Analysis and antitrust implications. New York: Free Press.

Wolf A./Swift J.B./Swinney H.L./Vastano J.A. (1985): Determining Lyapunov Exponents from a Time Series. In: Physica D, 16: 285-317.

Zvonkin A.K./Levin L.A. (1970): The Complexity of Finite Objects and the Development of the Concepts of Information and Randomness by Means of the Theory of Algorithms. In: Russian Mathematics Surveys, 25 (6): 83-124. 